\title{
A Study of New Chinese Swordplay Movies in the Context of the Times
}

\author{
Minjun Zhu \\ City University of Hong Kong, 999077 \\ minjunzhu2-c@my.cityu.edu.hk
}

Keywords: new Chinese Swordplay Movies; modern technology; research

\begin{abstract}
It has been more than 80 years since the development of Chinese Swordplay Movies. In different historical periods, due to the influence of social background and other factors, the Chinese Swordplay Movies created in each stage are not the same, but they are always inseparable from the social reality at that time. In the 1990s, New Chinese Swordplay Movies began to rise then entered a prosperous period. Generally speaking, modern technology was used to package the traditional Swordplay Movie, and the orientation of traditional value became diversified.
\end{abstract}

\section{The birth of new Chinese Swordplay Movies}

\subsection{Definition}

Chinese Swordplay Movies film is attached to traditional Chinese culture and developed to show the audience the core value and connotation of it. It is a type with unique Chinese characteristics rooted in Chinese traditional culture. "Wuxia" not only uses fights to attract the audience's attention, but also pays attention to a kind of traditional ethics of "Chivalry" and "righteousness". They have made a lot of breakthroughs and changes in the traditional types. And the hero image has become an individual, then the pursuit of the temple has become a new interpretation, also the use of digital technology as the basis of visual wonders has changed the traditional design of actions, and thus brought new vitality to the Chinese Swordplay Movies.

\subsection{The construction of new Chinese Swordplay Movies}

The new Chinese Swordplay Movies is different from the traditional ones. It means that when undertaking the past films, it also needs to have the new innovation and thinking. The development of modern science and technology has brought opportunities for the Chinese Swordplay Movies and accomplished many impossible things.

China's new Chinese Swordplay Movies appeared in the 1990s. There are many types of Swordplay Movies, showing a prosperous scene. Although some Swordplay Movies have changed the traditional films, the traditional ones are still the theme. These works break through the development mode of traditional films. The emergence of the new Chinese Swordplay Movies has saved the audience's tired vision. And they uses the creation mode and digital special effects to make these audiences applaud.

\section{The inheritance and development of new Chinese Swordplay Movies}

\subsection{Inheritance of traditional culture}

Chinese Swordplay Movies have always had commercial attributes. It is an embodiment of Chinese culture. It is the use of camera to express the most representative and core spirit of Chinese Swordplay Movies.

\subsubsection{Visual effect}

Shortly after the birth of the films, Chinese Swordplay Movies appeared in China also. In the eyes of many fans of Chinese Swordplay Movies, the most memorable Swordplay Movie in the early stage was "Burning the Red Lotus Temple", for special effects were used in making the film. 
In today's view, these techniques of special effects were simple and crude, but they were complementary to the development of technology at that time. It was in line with romantic supernatural films at that time, with strong characteristics. This method has not changed for many years. Until the 1980s, the advent of the era of Tsui Ke, was specially invited from foreign companies of special effects to perform special effects production, which was another development and progress of Chinese Swordplay Movies.

\subsubsection{Creation of artistic conception}

In the Chinese Swordplay Movies, the most attractive thing is not only the fighting scenes, but also the beautiful scenery with the oriental style. The hero combines with the characteristic oriental scenes, and then conforms to the theme of the films to create an indescribable artistic conception. While watching Chinese Swordplay Movies, the audience also pays attention to the connotation of them.

\subsubsection{The art of "Acrobatic fighting"}

In Chinese Swordplay Movies, it is essential to show Chinese Kung Fu. In recent years, the reputation of Chinese Kung $\mathrm{Fu}$ is well-known at home and abroad, and many foreign audiences come to China from afar to see this unique skill. So Kung $\mathrm{Fu}$ is not only an art, but also a knowledge. It not only has the consideration of posture, but also requires connotation.

\subsection{Chivalry}

Chivalry in Chinese Swordplay Movies refers to chivalrous men and spirit. The reason why the Swordplay Movies can be loved by so many people is that in addition to those heroes with high skills, the most important, is the key to Chinese Swordplay Movies. The spirit of chivalry can be said to represent precious virtue in the blood of Chinese people. Therefore, it is projected into the culture of Swordplay Movies.

After the 1950s, Chinese Swordplay Movies began to have some changes. The spirit of them is not only reflected in the behavior of heroes, but also reflected in their attitudes. In the 1990s, the scope of the spirit has gradually expanded. It has become a kind of embellishment. And it has been infused into the meaning of the times, and it is no longer just a simple truth and sermon.

\subsection{Transformation of chivalrous image}

Whether it is the behavior of chivalry, or attitude, or the mark of the times, the spirit of chivalry in the movies has always been more and more perfect in the development of history, and the heroes have also changed accordingly. The audience and movies fans have the same respect for heroes, for they never fear life and death.

In the new Chinese Swordplay Movies, the heroes changed a lot which are unlike the previous characters in the world. They are no longer as decent as before. The heroes in the new Chinese Swordplay Movie may be lustful and greedy like Wei Xiaobao, and their characters are much fuller than those in the previous movies.

\subsection{Interpretation of implication}

The traditional theme of chivalry gives way to the reform of the country and turns the theme of Chinese Swordplay Movies from advocating filial piety to reality. The new Chinese Swordplay Movies has a strong sensitivity to reality, fundamentally "subverts the myth that the swordsman always wins and the Chinese Swordplay Movies are invincible".

The Swordplay Movies are constantly changing in order to meet the needs of the public. Among them, the changes in the performance content of the movies bear the brunt. In the past, the heroes in the Chinese Swordplay Movies were generally a little bit of facial makeup. They were always the side of justice and had no selfish desire. But with the development, the value orientation of Chinese Swordplay Movies has also changed. Therefore, the new Swordplay Movies are gradually changing the forms. In order to meet the audience's aesthetic requirements, they put the principle of special effects in the highest position. 


\section{New swordsman--production and consumption under digital technology}

\subsection{Types of films and audience aging}

In recent years, with the rapid development of science and technology, all kinds of films have tried their best to develop. In short, the forms of films present a trend of diversified development. At this time, the glory of Swordplay Movies has been difficult to resist invasion, and the box offices of them tend to decline. Chinese Swordplay Movies as a unique type of movies in China became difficult to develop. In addition, with the change of audience's aesthetic requirements, they are also facing many crises. Therefore, it is necessary to innovate the types of Swordplay Movies.

\subsection{Commercial attributes of new Chinese Swordplay Movies}

Since its creation, Chinese Swordplay Movies have been defined as the type of commercial films. In them, there wound be fascinating arena, robbing the rich and helping the poor, raping Correctional forces and eliminating evil, and having confidantes accompanied. There are also confidantes, long love, family, country, and the world, and so on. A series of Chinese Swordplay Movies have been labeled with their own style by directors, showing their own characteristics, absolutely with commercial attributes. The new Chinese Swordplay Movies must be familiar with psychology, and combine them with the times, in order to achieve success in both artistic and commercial aspects.

\subsection{Chinese Swordplay Movies under special effects}

The films began to be fully digitized from the beginning of the preparation to the late completion. The cost of the original films is very high, while the quality of them is not high also, and it is not easy to save too. That's why many early films can not be seen today. However, it is precisely because of digital technology that some films with research value in the past have been converted into digital ones. The development of digital technology has greatly improved the film production. With the development of technology, many scenes that people dream about have been realized, and the dream has been turned into reality. The art of film has been infinitely extended and greatly enriched.

One of the reasons why the audience like to watch Swordplay Movies is that they benefit from the actions in them. Because of this, Chinese Swordplay Movies give digital technology a room for use in actions. Character modeling, the scene design and actions all present the characteristics of spectacle. But because of this, the audience only see these spectacles, then ignore the subject matters of Chinese Swordplay Movies. Nowadays, many Swordplay Movies on the market tend to have simple plots, but the forms of expression are too fancy. The audience also only pay attention to the spectacle effect while ignoring others. However, the times are changing, and the situation of movies is also changing. In recent years, the situation of relying on fights only has been broken. In this way, Chinese Swordplay Movies can create all kinds of spectacles through digital technology. Although the advent of digital technology can present a visual feast, it will also lead to excessive dependence on technology.

\section{References}

[1] Yuan Ye. Researches on the new trend of Chinese Swordplay Movies film creation [D]. Modern Communication, 2016.

[2] Suo Yabin. Aesthetic style of Hong Kong action films [J]. Beijing: Communication University of China Press, 2010.

[3] Weng Jieting. The rise of Chinese Swordplay Movies movies in the new era from Xu Haofeng's works [J]. Film Review. October 2016. 